\title{
Effectiveness of hospital emergency department regionalization and categorization policy on appropriate patient emergency care use: a nationwide observational study in Taiwan
}

Chih-Yuan Lin ${ }^{1,2,3,4}$ and Yue-Chune Lee ${ }^{2,3 *}$

\begin{abstract}
Background: Emergency department (ED) overcrowding is a health services issue worldwide. Modern health policy emphasizes appropriate health services utilization. However, the relationship between accessibility, capability, and appropriateness of ED use is unknown. Thus, this study aimed to examine the effect of hospital ED regionalization policy and categorization of hospital emergency capability policy (categorization policy) on patient-appropriate ED use.
\end{abstract}

Methods: Taiwan implemented a nationwide three-tiered hospital ED regionalization and categorization of hospital emergency capability policies in 2007 and 2009, respectively. We conducted a retrospective observational study on the effect of emergency care policy intervention on patient visit. Between 2005 and 2011, the Taiwan National Health Insurance Research Database recorded 1,835,860 ED visits from 1 million random samples. ED visits were categorized using the Yang-Ming modified New York University-ED algorithm. A time series analysis was performed to examine the change in appropriate ED use rate after policy implementation.

Results: From 2005 to 2011, total ED visits increased by 10.7\%. After policy implementation, the average appropriate ED visit rate was 66.9\%. The intervention had no significant effect on the trend of appropriate ED visit rate.

Conclusions: Although regionalization and categorization policies did increase emergency care accessibility, it had no significant effect on patient-appropriate ED use. Further research is required to improve data-driven policymaking.

Keywords: Emergency care, Utilization, Appropriate, Regionalization, Categorization, Policy, NYU-ED algorithm, Observational study

\footnotetext{
* Correspondence: yclee@ym.edu.tw

${ }^{2}$ Institute of Health and Welfare Policy, School of Medicine, National

Yang-Ming University, Taipei, Taiwan

${ }^{3}$ Master Program in Trans-disciplinary Long-Term Care and Management,

National Yang-Ming University, Taipei, Taiwan

Full list of author information is available at the end of the article
}

(c) The Author(s). 2021 Open Access This article is licensed under a Creative Commons Attribution 4.0 International License, which permits use, sharing, adaptation, distribution and reproduction in any medium or format, as long as you give appropriate credit to the original author(s) and the source, provide a link to the Creative Commons licence, and indicate if changes were made. The images or other third party material in this article are included in the article's Creative Commons licence, unless indicated otherwise in a credit line to the material. If material is not included in the article's Creative Commons licence and your intended use is not permitted by statutory regulation or exceeds the permitted use, you will need to obtain permission directly from the copyright holder. To view a copy of this licence, visit http://creativecommons.org/licenses/by/4.0/. The Creative Commons Public Domain Dedication waiver (http://creativecommons.org/publicdomain/zero/1.0/) applies to the data made available in this article, unless otherwise stated in a credit line to the data. 


\section{Background}

The American Medical Association and American College of Emergency Physicians published guidelines for the categorization and regionalization of hospital-based emergency department (ED) capability to integrate network emergency care and match critically ill patients with the appropriate healthcare facility [1-3]. Kocher et al. [4] proposed definitions and a conceptual framework for the categorization, designation, and regionalization of emergency care policy evaluation criteria. These theoretical guidelines significantly influence the development of emergency care delivery systems worldwide.

The categorization policy focuses on all emergency care capability and capacity of a hospital, whereas the regionalization policy matches medical resources to patients' needs to maximize health benefits and outcomes while minimizing the cost and use of resources over a specified geographic area [5]. Empirical data regarding emergency care categorization [5-13] and regionalization [14-21] have demonstrated their effectiveness. However, most studies focus on specific time-sensitive disease entities, age groups, or regional scales. Moreover, data show that categorization, designation, and regionalization policies may improve the transparency of emergency care services by disclosing quality information about the capability levels of prehospital emergency medical services, EDs, and hospital emergency services, but changes in health care-seeking behavior as a result of categorization and regionalization information are unclear [4].

ED overcrowding is a health services research issue [2226] that may profoundly jeopardize patient safety [27-32]. According to the Asplin ED crowding input-throughputoutput conceptual model, patient flow management may drive ED crowding research [33]. This model proposed that ED crowding may be caused by (1) the input dimension represented by inappropriate ED use by patients, and (2) inadequate accessibility and emergency physician capability in emergency care supplied by providers [33].

Aday and Andersen noted that health policy may improve access, thus increasing realized utilization [34]. Contemporary health policy is driven by an emphasis on appropriate health services utilization, avoiding overuse, misuse, or underuse [35]. However, the relationship between accessibility, capability, and appropriateness of ED use remains unknown. Therefore, we hypothesized that regionalization and categorization policies may increase user access, and emergency care quality and capability information disclosure may guide patients when choosing an "appropriate" treatment setting, thereby improving appropriate ED care use rate. Thus, this study aimed to investigate the effect of these policies on patient-appropriate ED use.

\section{Methods}

\section{Setting}

The Taiwan Ministry of Health and Welfare (MoHW) adopted the categorization, designation, and regionalization international guidelines to establish a national emergency care system, including prehospital emergency medical services (EMS), emergency medical responder-responsive hospital designation, regionalization, and categorization of hospital emergency capability. Taiwan's ED regionalization and categorization policies were implemented in 2007 and 2009 , respectively, with the primary goals of establishing infrastructure and decreasing regional disparity.

\section{Study design and timelines}

This seven-year retrospective observational study on the effect of hospital emergency care policies on patientappropriate ED use included all ED visits between January 1, 2005 and December 31, 2011. Each visit date was associated with one event to avoid replicating events (Fig. 1). We divided the study period in three: the prepolicy period (August 2005-July 2007), regionalization policy intervention period (August 2007-July 2009), and categorization policy intervention period (August 2009July 2011).

\section{Regionalization policy}

The regionalization policy focuses on prehospital EMS networking and rescuer-responsive hospital ED designations. Its primary objective was to increase the accessibility of emergency care. To achieve this objective, health authorities first identified responsible hospitals in 61 subregions; subsequently, every subregion had at least one hospital that was designated to respond to acute events.

In July 2007, Taiwan launched the Emergency Medical Services Act Amendment. The revised Emergency Medical Services Act represented a landmark for reorganizing the network of emergency care systems in Taiwan; this act implemented three significant changes: (1) introducing hospital-based ED categorization focused on ED medical capability to provide resuscitation, (2) establishing a medical director system to connect hospital ED physicians with prehospital EMS, and (3) forming six regional emergency operations centers (REOCs). Prehospital regionalization efforts included onsite auditing by the MoHW and the categorization of hospital-based ED using a three-tiered approach to emergency care (severe, moderate, and general). Moderate- and severe-tiered EDs undergo onsite audits by the MoHW, while generaltiered hospitals are overseen by the local health authority.

The hierarchical system of emergency rescuerresponsive hospitals and designated hospital ED must provide transport within $30 \mathrm{~min}$ for time-sensitive events such as stroke, acute myocardial infarction, major trauma, high-risk pregnancies, and newborns. Six REOCs may dispatch EMS ambulances and rescue personnel from local hospitals to emergency patients 


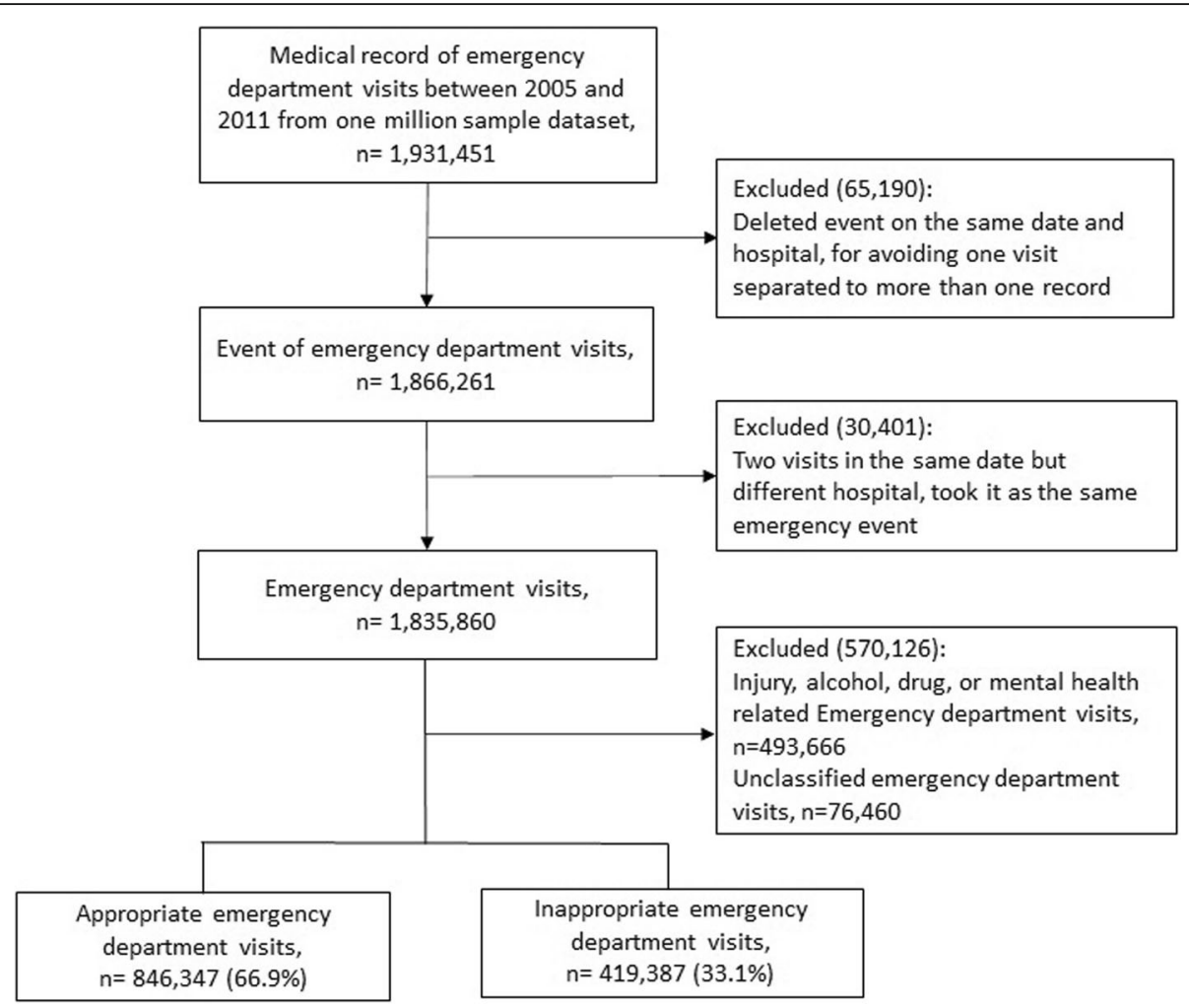

Fig. 1 Flow chart of emergency department visits

and mass casualties. The REOC coordinates with the EMS to provide onsite prehospital triage and care, and dispatches patients to the nearest designated appropriate hospital ED.

\section{Categorization policy}

In 2009, the Taiwan MoHW promulgated the "Standards for the categorization of hospital emergency capability." According to these standards, the MoHW categorized hospitals into three tiers (severe, moderate, and general) based on their emergency care capability and capacity (including hospital ED, critical time-sensitive-event care teams, and intensive care unit). The primary focus of this policy was the establishment of centers for trauma, cardiac catheterization, stroke, perinatal emergency care conditions, high-risk pregnancies, and pediatric intensive care.

The Joint Commission of Taiwan accredits hospitals every 3 years, and severe-tiered hospitals are considered the last line for hospital referrals. At the end of 2009, 191 rescuer-responsive hospitals were accredited, including 26 severe-, 76 moderate-, and 89 general-tiered hospitals. This policy ensures the use of timely, continuous, effective, and collaborative multidisciplinary methods with two principal objectives: (1) to provide quality hospital emergency care, and (2) to provide a hospital emergency care capability classification with information regarding whether patients chose the appropriate treatment setting (right care in the right place). This information provides patients with appropriate quality information to increase the appropriate ED use. Therefore, the prehospital EMS, hospital ED, hospital emergency care teams, and intensive care unit critical care capability and capacity were well established and categorized in Taiwan [36].

\section{Estimated appropriate ED use}

We used a revised version of the Modified Billings/New York University-ED algorithm (NYU-ED algorithm) for emergency care evaluation according to processes and outcome indicators-referred to as the Yang-Ming modified NYU-ED algorithm - to define the appropriateness of ED use (Additional Fig. 1) [37]. This algorithm classifies ED visits as emergent vs. nonemergent, and optimal care site as ED vs. primary care. It further divides an ED visit into six categories: (1) "nonemergent" (NE), (2) "emergent, primary care treatable" (EPC), (3) "emergent care needed, preventable/avoidable" (EPA), (4) "emergent care needed, not preventable/avoidable" (ENPA), (5) unclassifiable, and (6) "injury and behavioral health-related diagnosis" [38].

The Modified Billings/NYU-ED algorithm classifies ED use as appropriate when EPA and ENPA summative primary diagnosis probabilities are equal to or greater 
than 0.50, whereas $\mathrm{NE}$ and PCT are classified as inappropriate ED use [39-41].

We reclassified inappropriate and unclassifiable ED visits using explicit procedures (if a patient received any procedure that is not often available in primary care settings, such as computed tomography or magnetic resonance imaging scans), and outcome-based criteria (if a patient is transferred, hospitalized, or dies) to reflect the complexity of a patient's condition and appropriateness of emergency care usage. Injury and behavioral health ICD-9 codes were excluded as the original Billings/ NYU-ED algorithm [38].

\section{Data access and covariates}

The analytic data were derived from the Taiwan Longitudinal Health Insurance Database 2005 (LHID2005), which is maintained with routinely collected administrative data from the National Health Insurance [42, 43]. The LHID2005 comprises 1 million randomly sampled participants who were alive in 2005; the database includes all medical records for these individuals from 1995 onward. It also includes hospital and medical professional staff characteristics, subject enrollment, and medical information. This database reflects healthcare facilities' accessibility and medical care utilization [44, 45]. The collected medical utilization information includes diagnosis procedure, treatment medication, medical cost, date of visit, and deposition [46]. The accuracy of the diagnoses recorded by the LHID2005 for time-sensitive diseases, such as acute ischemic stroke $[47,48]$, acute myocardial infarction [48], asthma [49] and pneumonia [50], has been validated. Encrypted unique personal identification numbers link all the data, allowing a longitudinal follow-up.

We identified ED visits using the ED visit case type and revenue codes. We used these data to count ED visits. We obtained visit-level data for all ED visits to all hospitals in Taiwan from 2005 to 2011. The covariates included predisposing factors such as sex, age, and occupation; enabling factors such as the beneficiary's insured salary, urbanization of living area, and emergency care resources classification; and need-driven factors such as comorbidity status. Comorbidity status was defined using the Charlson Comorbidity Index (CCI) score [51].

\section{Statistical analyses}

We compared the two policy periods' baseline covariates characteristics using $X^{2}$ tests and t-tests accounting for the LHID2005 administrative data. Because ED use and its covariates are time-dependent and longitudinal, we performed a time series analysis to estimate multilevel changes in appropriate ED use rates after regionalization and categorization policy interventions. Before examining the policy's effect on appropriate ED visit rates, the Dickey-Fuller test was used to determine the baseline appropriate use rate. The difference in monthly mean probabilities after hospital ED regionalization and categorization was determined using a segmented autoregressive integrated moving average (ARIMA) model with an indicator variable for the regionalization and categorization periods. This model can examine the policy intervention effect while accounting for autocorrelation and time effects. We also evaluated the odds of having an appropriate ED visit during the regionalization and categorization policy stage compared with previous policy stage. All analyses were conducted using SAS 9.4 (SAS Institute, Cary, NC) and Stata MP 14.0 (StataCorp LLC, College Station, TX) software. Statistical significance was determined using a two-tailed significance level of 0.05 .

\section{Sensitivity and Bias analyses}

According to a systematic review on ED crowding, the common causes of input factors are nonurgent visits, frequent flyers, and influenza season [52]. During our study period, no specific ED-related policy was promulgated nor was the ED co-payment scheme changed. We evaluated the effects of frequent ED users $(\geq 4$ visits per year) [53] (Additional Fig. 2) and the 2009 influenza season (Additional Fig. 3) [54]. Excluding the effects related to these factors, the trend in appropriate ED visit classification showed no substantial changes. A sensitivity analysis was conducted increasing the threshold of EPA and ENPA summation probabilities to $\geq 0.75$ (Additional Fig. 4). Similar trends in ED visit classification further demonstrated the lack of significant changes.

\section{Results}

\section{Emergency Care access}

From 2005 to 2011, the number of ED visits, ED expanse, and ED physicians increased by 10.7, 29.4, and $35.1 \%$, respectively. In contrast, the total number of hospitals and EDs decreased by 8.1 and $8.6 \%$, respectively, during the same period (Additional Table 1).

\section{Participant characteristics}

Between 2005 and 2011, 1,931,451 ED visits were identified from 1 million random sample datasets. Thus, the study sample comprised 1,866,261 events (Fig. 1). Of these, 65,190 events on the same date and at the same hospital were excluded to avoid visit replication. When two visits occurred on the same date but at different hospitals $(30,401$ cases), both visits were considered the same emergency event. A total of 76,460 visits related to injury and behavioral ICD-9 diagnoses were excluded from the modified Billings/NYU-ED algorithm for international comparison. In this study cohort, the crude appropriate ED visit rate was $66.9 \%$. Table 1 presents the numbers and percentages of baseline characteristics of ED visits by policy intervention for observable samples. 
During the pre-policy period, the mean age of patients was $39.6 \pm 26.2$ years; after regionalization policy implementation, $44.8 \pm 25.3$ years; and after categorization policy implementation, $46.2 \pm 24.5$ years. During the prepolicy period, the mean CCI score of patients was $1.0 \pm$ 1.9; after regionalization policy implementation, $1.2 \pm 2.1$; and after categorization policy implementation, $1.2 \pm 2.1$.

\section{Appropriate ED visit rate by baseline characteristics for different policy interventions}

Table 2 presents the overall rate of appropriate ED visits after regionalization policy implementation (64.1\% prepolicy period vs. $68.1 \%$ regionalization policy stage); no significant changes occurred after the categorization policy was implemented (68.1\% vs. $68.5 \%)$. Patients with a higher rate of appropriate ED use had the following characteristics: male, aged $\geq 65$ years, CCI score $>1$, rural region residents, residents of an area with inadequate emergent care resources, weekday ED visit, income level in the third quintile, and occupations such as civil servants, teachers, military personnel, and veterans.

\section{Time series analysis of the policy intervention effect}

Figure 2 presents the results of the segmented ARIMA analyses examining the relationship between regionalization and categorization policies and appropriate ED use rate. For the rate of appropriate ED visits during the study period, there was no significant change in intercept points (level parameters). Table 2 presents results showing a statistically significant change in the average appropriate ED visit rate as a result of the regionalization policy. The Dickey-Fuller test showed that the data remained stable before and after the implementation of the regionalization $(P=0.005)$ and categorization $(P=0.0037)$ policies. To fit the ARIMA model, we used the autocorrelation function (ACF) and partial autocorrelation function (PACF) to determine whether autoregressive (AR) or moving average processes terms were needed to address any autocorrelation. The plot of the appropriate ED rate by month showed an exponentially declining ACF and spikes in the first and eleventh lags of the PACF. Therefore, we used the AR term in this study.

We found that comorbidity mediated the association between appropriate ED visit rate and regionalization or categorization policy intervention (Table 3). In contrast, income had an inverse association with appropriate ED use rate. We performed a stratification analysis using the CCI. The population was classified into two groups: one with a CCI score equal to or less than 1 and the other with a CCI score greater than 1 (Additional Table 2). The CCI score subgroup analysis showed that, in both groups, the regionalization policy had a significant negative effect on appropriate ED visit rate (CCI score $\leq 1$ : trend change $-0.27 \%$ per month, $P=0.024$; CCI score > 1 : trend change $-0.16 \%$ per month, $P=0.015$ ).

\section{Discussion}

In this seven-year policy intervention observational study, ED utilization and expanse increased by 10.7 and $29.4 \%$, respectively. Provider-related ED policies had no significant medium-term effects (2 years) on patients' patterns of appropriate ED use and improved the realized accessibility to EDs.

Previous studies concluded that appropriate ED utilization varies according to insurance status, socioeconomic status, race, and other sociodemographic factors [7]. Nonetheless, need-driven factors were the most important predictors of appropriate ED use [55]. Conversely, common factors for inappropriate ED use include greater trust in the hospital than in the primary care setting [56], greater convenience [57], time saving [58, 59], or lack of primary care access [60]. One Taiwanese nationwide validation study reported that an increase in the availability of ambulatory care physicians or facilities did not decrease non-emergency ED use [61].

From the user's perspective, non-business hours, including evening and weekend, accounted for $76.2 \%$ of whole service period. Moreover, patients tend to seek immediate or ED services for time-sensitive events [62,63]. Our study determined that provider-side ED policy implementation and quality information disclosure did not increase patients' appropriate ED use. The lack of effect may be explained as follows: (1) prudent laypersons may have difficulty judging whether their condition is urgent or nonurgent, and where they should go for treatment [63]; and (2) the categorization of hospital emergency capability ensures the comprehensive availability of laboratory services, image studies, and treatment $24 \mathrm{~h}$ a day/365 days a year.

The unintended consequence of hospital emergency care quality disclosure is that the hospital ED becomes the first choice for people seeking treatment for timesensitive emergency conditions or convenience. The Taiwan MoHW proposed a co-payment of $\$ 12$ for an ED visit to possibly reduce primary care-treatable ED visits. However, the National Health Insurance medical service payment standards dictate that the co-payments for a medical center ED, regional hospital ED, and local hospital ED visit are $\$ 15, \$ 10$, and $\$ 5$, respectively. In comparison, the co-payment for an outpatient clinic visit at a medical center is $\$ 12$; at a regional hospital, $\$ 8$; at a local hospital, \$2.7; and at a general practitioner office, $\$ 1.7$. Other factors that must be considered are traffic and waiting time costs in the primary care setting, as well as a minimum wage of $\$ 4.50$ per hour [64]. Meanwhile, a nationwide emergency policy requires the hospital emergency care system to improve its abilities to meet patients' needs by improving accessibility through 
Table 1 The baseline characteristic among the emergency department visit patients by policy intervention

\begin{tabular}{|c|c|c|c|c|c|c|}
\hline & \multicolumn{3}{|c|}{ Regionalization Policy Intervention } & \multicolumn{3}{|c|}{ Categorization Policy Intervention } \\
\hline & \multirow{2}{*}{$\begin{array}{l}\text { Pre-policy period } \\
(n=475,991) \\
\text { n (\%) }\end{array}$} & \multicolumn{2}{|l|}{$\begin{array}{l}\text { Regionalization } \\
\text { period }(n=340,870)\end{array}$} & \multirow{2}{*}{$\begin{array}{l}\text { Regionalization } \\
\text { period }(n=340,870) \\
n(\%)\end{array}$} & \multicolumn{2}{|l|}{$\begin{array}{l}\text { Categorization } \\
\text { period }(n=448,873)\end{array}$} \\
\hline & & n (\%) & $\begin{array}{l}P \\
\text { Value }\end{array}$ & & n (\%) & $\begin{array}{l}P \\
\text { Value }\end{array}$ \\
\hline \multicolumn{7}{|l|}{ Sex } \\
\hline Female & $240,804(50.6)$ & $173,685(51.0)$ & 0.034 & $173,685(51.0)$ & $228,441(50.9)$ & 0.72 \\
\hline Male & $235,187(49.4)$ & $167,185(49.0)$ & & $167,185(49.0)$ & $220,432(49.1)$ & \\
\hline \multicolumn{7}{|l|}{ Age } \\
\hline$<18$ & $116,178(24.4)$ & $58,052(17.0)$ & $<0.001$ & $58,052(17.0)$ & $65,081(14.5)$ & $<0.001$ \\
\hline $18-64$ & $251,361(52.8)$ & $189,921(55.7)$ & & $189,921(55.7)$ & $261,301(58.2)$ & \\
\hline$\geq 65$ & $108,452(22.8)$ & $92,897(27.3)$ & & $92,897(27.3)$ & $122,491(27.3)$ & \\
\hline \multicolumn{7}{|l|}{ Charlson Comorbidity Index } \\
\hline $\mathrm{CCl} \leq 1$ & $371,818(78.1)$ & $251,609(73.8)$ & $<0.001$ & $251,609(73.8)$ & $328,616(73.2)$ & 0.002 \\
\hline $\mathrm{CCl}>1$ & $104,173(21.9)$ & $89,261(26.2)$ & & $89,261(26.2)$ & $120,257(26.8)$ & \\
\hline \multicolumn{7}{|l|}{ Place of residence } \\
\hline Urban & $119,532(25.1)$ & $86,117(25.3)$ & 0.11 & $86,117(25.3)$ & $114,076(25.4)$ & 0.58 \\
\hline Suburban & $147,321(31.0)$ & $105,668(31.0)$ & & $105,668(31.0)$ & $138,697(30.9)$ & \\
\hline Rural & $202,969(42.6)$ & $145,196(42.6)$ & & $145,196(42.6)$ & $190,850(42.5)$ & \\
\hline Missing & $6169(1.3)$ & $3889(1.1)$ & & $3889(1.1)$ & $5250(1.2)$ & \\
\hline \multicolumn{7}{|l|}{ Place of ED resources } \\
\hline Sufficient area & $385,958(81.1)$ & $277,692(81.5)$ & 0.005 & $277,692(81.5)$ & $364,120(81.1)$ & 0.012 \\
\hline Insufficient area & $90,033(18.9)$ & $63,178(18.5)$ & & $63,178(18.5)$ & $84,753(18.9)$ & \\
\hline \multicolumn{7}{|l|}{ Day of visit } \\
\hline Weekday & $306,106(64.3)$ & $220,022(64.5)$ & 0.030 & $220,022(64.5)$ & $291,980(65.0)$ & $<0.001$ \\
\hline Weekend & $169,885(35.7)$ & $120,848(35.5)$ & & $120,848(35.5)$ & $156,893(35.0)$ & \\
\hline \multicolumn{7}{|l|}{ Income level } \\
\hline Quintile 1 (Lowest) & $163,027(34.3)$ & $34,632(10.2)$ & $<0.001$ & $34,632(10.2)$ & $45,746(10.2)$ & $<0.001$ \\
\hline Quintile 2 & $43,972(9.2)$ & $105,197(30.9)$ & & $105,197(30.9)$ & $134,040(29.9)$ & \\
\hline Quintile 3 & $124,805(26.2)$ & $85,505(25.1)$ & & $85,505(25.1)$ & $37,760(8.4)$ & \\
\hline Quintile 4 & $46,384(9.7)$ & $40,680(11.9)$ & & 40,680 (11.9) & $126,315(28.1)$ & \\
\hline Quintile 5 (Highest) & $95,135(20.0)$ & $70,695(20.7)$ & & $70,695(20.7)$ & $98,837(22.0)$ & \\
\hline Missing & $2668(0.6)$ & $4161(1.2)$ & & $4161(1.2)$ & $6175(1.4)$ & \\
\hline \multicolumn{7}{|l|}{ Occupation } \\
\hline $\begin{array}{l}\text { Dependents of the insured } \\
\text { individuals }\end{array}$ & $205,782(43.2)$ & $128,140(37.6)$ & $<0.001$ & $128,140(37.6)$ & $156,843(34.9)$ & $<0.001$ \\
\hline $\begin{array}{l}\text { Civil servants, teachers, military } \\
\text { personnel, and veterans }\end{array}$ & $22,276(4.7)$ & $24,607(7.2)$ & & $24,607(7.2)$ & $31,548(7.0)$ & \\
\hline $\begin{array}{l}\text { Nonmanual workers and } \\
\text { professionals }\end{array}$ & $83,206(17.5)$ & $60,068(17.6)$ & & $60,068(17.6)$ & $87,623(19.5)$ & \\
\hline Manual workers & $114,506(24.1)$ & $92,937(27.3)$ & & $92,937(27.3)$ & $126,101(28.1)$ & \\
\hline Other & $47,737(10.0)$ & $31,090(9.1)$ & & $31,090(9.1)$ & $40,696(9.1)$ & \\
\hline Missing & $2484(0.5)$ & $4028(1.2)$ & & $4028(1.2)$ & $6062(1.4)$ & \\
\hline
\end{tabular}

Note: The policy of regionalization started on 13 July 2007. Moreover, the policy of categorization began on 13 July 2009. However, using the 31 July 2007 and 31 July 2009 as the cut of point 
Table 2 Appropriate rate by baseline characteristic on different policy intervention

\begin{tabular}{|c|c|c|c|c|c|c|}
\hline & \multicolumn{3}{|c|}{ Regionalization Policy Intervention, $n=816,861$} & \multicolumn{3}{|c|}{ Categorization Policy Intervention, $n=789,743$} \\
\hline & \multirow{2}{*}{$\begin{array}{l}\text { Pre-policy period } \\
(n=475,991) \\
\text { No of } \\
\text { Appropriate ED } \\
\text { Visit }(\%)\end{array}$} & \multirow{2}{*}{$\begin{array}{l}\text { Regionalization } \\
\text { period }(n=340,870) \\
\text { No of Appropriate } \\
\text { ED Visit }(\%)\end{array}$} & \multirow[b]{2}{*}{$P$ Value } & \multirow{2}{*}{$\begin{array}{l}\text { Regionalization } \\
\text { period }(n=340,870) \\
\text { No of Appropriate } \\
\text { ED Visit (\%) }\end{array}$} & \multirow{2}{*}{$\begin{array}{l}\text { Categorization } \\
\text { period ( } n=448,873 \text { ) } \\
\text { No of Appropriate } \\
\text { ED Visit }(\%)\end{array}$} & \multirow[b]{2}{*}{$P$ Value } \\
\hline & & & & & & \\
\hline Total & $305,116(64.1)$ & $233,970(68.6)$ & $<0.001$ & $233,970(68.6)$ & $307,261(68.5)$ & 0.17 \\
\hline \multicolumn{7}{|l|}{ Sex } \\
\hline Female & $153,088(63.6)$ & $117,849(67.9)$ & $<0.001$ & $117,849(67.9)$ & $154,642(67.7)$ & 0.38 \\
\hline Male & $152,028(64.6)$ & $116,121(69.5)$ & $<0.001$ & $116,121(69.5)$ & $152,619(69.2)$ & 0.28 \\
\hline \multicolumn{7}{|l|}{ Age } \\
\hline$<18$ & $43,598(37.5)$ & $21,956(37.8)$ & 0.29 & $21,956(37.8)$ & $23,658(36.4)$ & $<0.001$ \\
\hline $18-64$ & $165,836(66.0)$ & $129,437(68.2)$ & $<0.001$ & $129,437(68.2)$ & $174,718(66.9)$ & $<0.001$ \\
\hline$\geq 65$ & $95,682(88.2)$ & $82,577(88.9)$ & 0.006 & $82,577(88.9)$ & $108,885(88.9)$ & 1.00 \\
\hline \multicolumn{7}{|l|}{ Charlson Comorbidity Index } \\
\hline $\mathrm{CCl} \leq 1$ & $211,153(56.8)$ & $153,181(60.9)$ & $<0.001$ & $153,181(60.9)$ & $198,990(60.6)$ & 0.027 \\
\hline $\mathrm{CCl}>1$ & $93,963(90.2)$ & $80,789(90.5)$ & 0.21 & $80,789(90.5)$ & $108,271(90.0)$ & 0.078 \\
\hline \multicolumn{7}{|l|}{ Place of residence } \\
\hline Urban & $72,188(60.4)$ & $55,220(64.1)$ & $<0.001$ & $55,220(64.1)$ & $72,620(63.7)$ & 0.13 \\
\hline Suburban & $92,955(63.1)$ & $71,748(67.9)$ & $<0.001$ & $71,748(67.9)$ & $93,557(67.5)$ & 0.058 \\
\hline Rural & $136,783(67.4)$ & $104,686(72.1)$ & $<0.001$ & $104,686(72.1)$ & $138,021(72.3)$ & 0.25 \\
\hline Missing & $3190(51.7)$ & $2316(59.6)$ & $<0.001$ & 2316 (59.6) & $3063(58.3)$ & 0.32 \\
\hline \multicolumn{7}{|l|}{ Place of ED resources } \\
\hline Sufficient area & $245,981(63.7)$ & $189,216(68.1)$ & $<0.001$ & $189,216(68.1)$ & $246,829(67.8)$ & 0.021 \\
\hline Insufficient area & $59,135(65.7)$ & $44,754(70.8)$ & $<0.001$ & $44,754(70.8)$ & $60,432(71.3)$ & 0.12 \\
\hline \multicolumn{7}{|l|}{ Day of visit } \\
\hline Weekday & $207,817(67.9)$ & $159,223(72.4)$ & $<0.001$ & $159,223(72.4)$ & $210,381(72.1)$ & 0.042 \\
\hline Weekend & $97,299(57.3)$ & $74,747(61.9)$ & $<0.001$ & $74,747(61.9)$ & $96,880(61.7)$ & 0.61 \\
\hline \multicolumn{7}{|l|}{ Income level } \\
\hline Quintile 1 (Lowest) & $105,959(65.0)$ & $20,879(60.3)$ & $<0.001$ & $20,879(60.3)$ & $27,629(60.4)$ & 0.79 \\
\hline Quintile 2 & $29,545(67.2)$ & $77,534(73.7)$ & $<0.001$ & $77,534(73.7)$ & $98,340(73.4)$ & 0.13 \\
\hline Quintile 3 & $85,307(68.4)$ & $62,461(73.0)$ & $<0.001$ & $62,461(73.0)$ & $25,495(67.5)$ & $<0.001$ \\
\hline Quintile 4 & $27,359(59.0)$ & $26,183(64.4)$ & $<0.001$ & $26,183(64.4)$ & $89,831(71.1)$ & $<0.001$ \\
\hline Quintile 5 (Highest) & $55,478(58.3)$ & $44,571(63.0)$ & $<0.001$ & $44,571(63.0)$ & $62,849(63.6)$ & 0.060 \\
\hline Missing & $1468(55.0)$ & $2342(56.3)$ & 0.36 & $2342(56.3)$ & 3117 (50.5) & $<0.001$ \\
\hline \multicolumn{7}{|l|}{ Occupation } \\
\hline $\begin{array}{l}\text { Dependents of the insured } \\
\text { individuals }\end{array}$ & $113,133(55.0)$ & $78,377(61.2)$ & $<0.001$ & $78,377(61.2)$ & $97,312(62.0)$ & 0.001 \\
\hline $\begin{array}{l}\text { Civil servants, teachers, military } \\
\text { personnel, and veterans }\end{array}$ & $17,384(78.0)$ & $19,879(80.8)$ & $<0.001$ & $19,879(80.8)$ & 25,137 (79.7) & 0.012 \\
\hline $\begin{array}{l}\text { Nonmanual workers and } \\
\text { professionals }\end{array}$ & 49,789 (59.8) & $37,726(62.8)$ & $<0.001$ & $37,726(62.8)$ & $53,941(61.6)$ & $<0.001$ \\
\hline Manual workers & $88,197(77.0)$ & $72,606(78.1)$ & $<0.001$ & $72,606(78.1)$ & $97,322(77.2)$ & $<0.001$ \\
\hline Other & $35,280(73.9)$ & $23,154(74.5)$ & 0.22 & $23,154(74.5)$ & $30,531(75.0)$ & 0.20 \\
\hline Missing & $1333(53.7)$ & $2228(55.3)$ & 0.24 & $2228(55.3)$ & 3018 (49.8) & $<0.001$ \\
\hline
\end{tabular}

Using the chi-squared test to check the percentage of an emergent visit from all emergency department visit by subgroup; ED emergency department 


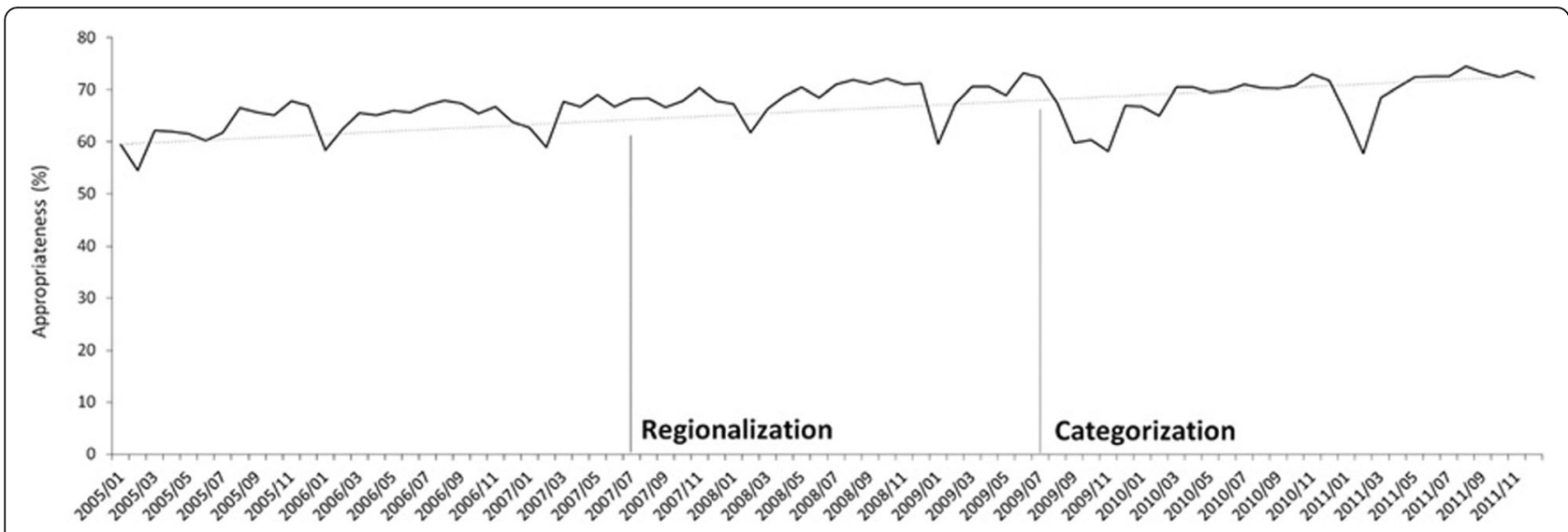

Fig. 2 The appropriate rate of emergency department visits during the period from 2005 to 2011 by policies intervention

increased convenience (e.g., providing immediate access to an ED anytime) and availability (e.g., providing consultations with an available specialist within $30 \mathrm{~min}$ ). Therefore, a hospital ED offers more significant time savings and cost-effectiveness for patients.

A systematic review reported that financial constraints and case management are two effective approaches to increase ED use appropriateness [65]. Raven et al. [65] suggested that financial measures may decrease ED visits without increasing appropriateness; conversely, case management may decrease ED visits while increasing appropriateness. We examined the effects of providerrelated policy and disclosure of related information on improving patients' appropriate ED use and found that this policy goal was unmet. We agree with Smulowitz's suggestion [66] to reshape emergency care and extend medical emergency services to meet patients' needs, such as offering real-time "face-to-face" telehealth to provide medical recommendations to support patient decisionmaking, and relieve patient anxiety, implementing an access policy that combines primary and ED care data without time or location limitations $[67,68]$.

\section{Strengths and limitations}

This study has several strengths: (1) we provided realworld empirical data to explain the relationship between ED policy intervention and patients' health-seeking behaviors; (2) we analyzed other possible causes of input factor increase (2009 influenza pandemic and frequent ED user effect) to ensure that the effects of policy implementation on appropriate ED use were not caused by other confounders; and (3) to the best of our knowledge, this study is the first nationwide single insurance system example that supports the American Medical Association, American College of Emergency Physicians, and

Table 3 The segmented autoregressive integrated moving average model analysis of the percentage of ED visit

\begin{tabular}{|c|c|c|c|c|c|c|}
\hline & \multicolumn{3}{|c|}{ Regionalization Policy Intervention } & \multicolumn{3}{|c|}{ Categorization Policy Intervention } \\
\hline & $\beta$ & SE & $P$ Value & $\beta$ & SE & $P$ Value \\
\hline Baseline trend & 0.06 & 0.05 & 0.25 & -0.08 & 0.06 & 0.16 \\
\hline Level change after policy intervention & -0.79 & 0.74 & 0.28 & -0.08 & 1.09 & 0.95 \\
\hline Trend change after policy intervention & -0.07 & 0.06 & 0.23 & 0.01 & 0.06 & 0.92 \\
\hline Percentage of female & 0.66 & 0.33 & 0.05 & 0.27 & 0.30 & 0.37 \\
\hline Mean Charlson score & 30.83 & 2.42 & $<0.001$ & 33.88 & 3.93 & $<0.001$ \\
\hline Percentage of residence in urban & 0.01 & 0.41 & 0.98 & 0.17 & 0.42 & 0.68 \\
\hline Percentage of insufficient emergency medical resources area & 0.26 & 0.39 & 0.51 & 0.18 & 0.52 & 0.73 \\
\hline Percentage of weekend & 0.04 & 0.05 & 0.36 & 0.06 & 0.07 & 0.40 \\
\hline Percentage of income level at quintile 1 (Lowest) & 0.08 & 0.04 & 0.04 & -0.19 & 0.95 & 0.84 \\
\hline Percentage of the dependents of the insured individuals & -0.13 & 0.14 & 0.35 & -0.29 & 0.12 & 0.02 \\
\hline AR1 & 0.05 & 0.17 & 0.77 & -0.04 & 0.19 & 0.82 \\
\hline
\end{tabular}

ED emergency department 
Kocher et al. theoretical models regarding the categorization, designation, and regionalization of emergency care. Thus, our study provides unique information for academic research in emergency care.

Conversely, this study has the following limitations that may impact its generalizability: (1) this retrospective study used a dataset collected for administrative claims purposes according to the conceptualization of appropriate ED visits, which may be defined at the patient, disease, hospital, and social context levels [69-75]. However, we did not have enough information to address these holistic concerns; (2) the LHID2005 administrative dataset is collected for reimbursement purposes, and there is natural attrition due to aging, migration, and death; (3) categorization and designation are essential components in the regionalization of emergency care networks [76]. However, Taiwan emergency care policy and services underwent an established regionalization and categorization sequence, and these paradigm differences deserve further investigation; and (4) in the market-maximized approach, financial and managed care strategies are chosen to drive improvement in appropriate ED use [77]. Contrastingly, Taiwan chose a market-minimized policy to guide appropriate ED use, which may limit the external validity of our study.

\section{Conclusion}

Among policies on international emergency care delivery systems, Taiwan's promotion of regionalization and categorization of emergency care policies has unique characteristics and requires evaluation. The providerside changes implemented by these policies did improve patient's accessibility to emergency care. In contrast, emergency care quality disclosure may not increase patients appropriate ED use. Strategies for balancing patients' needs and appropriate ED use require further investigation.

\section{Supplementary information}

The online version contains supplementary material available at https://doi. org/10.1186/s12913-020-06006-7.

Additional file 1: Figure 1. Yang-Ming modified New York UniversityEmergency Department Algorithm.

Additional file 2: Figure 2. Rate of appropriate emergency department visits excluding frequent users.

Additional file 3: Figure 3. Rate of appropriate emergency department visits excluding influenza patients.

Additional file 4: Figure 4. Rate of appropriate emergency department visits using a $\geq 0.75$ threshold.

Additional file 5: Table 1. Regionalization and categorization policyrelated statistics in Taiwan.

Additional file 6: Table 2. Segmented autoregressive integrated moving average model analysis of the percentage of emergency department visits according to Charlson comorbidity index groups.
Additional file 7: Table 3. Segmented autoregressive integrated moving average model analysis of the appropriate ED visit rate by the Charlson Comorbidity Index group.

\section{Abbreviations}

ACF: Autocorrelation function; AR: Autoregressive; ARIMA: Autoregressive integrated moving average; CCl: Charlson Comorbidity Index; ED: Emergency department; EMS: Emergency medical services; ENPA: Emergent, not preventable/avoidable; EPA: Emergent, preventable/avoidable;

EPC: Emergent, primary care; MoHW: Ministry of Health and Welfare; NE: Nonemergent; PACF: Partial autocorrelation function; REOC: Regional emergency operations center

\section{Acknowledgments}

We acknowledge the Taiwan National Health Insurance Research Database, which was provided by the National Health Insurance Administration and is managed by the National Health Research Institutes.

\section{Authors' contributions}

$\mathrm{C}-\mathrm{YL}$ and $\mathrm{Y}-\mathrm{CL}$ made substantial contributions to conception and design of this study. C-YL analysis and interpretation of data, and preparation of the manuscript. Y-CL critical appraisal and rewrite the manuscript to become an academic research paper. All authors have read and approved the manuscript.

\section{Funding}

The authors declare that they had no funding.

\section{Availability of data and materials}

The data that support the findings of this study are available from the Taiwan National Health Insurance Research Database, but restrictions apply to the availability of these data, which were used under license for the current study and so are not publicly available. Data are however available from the authors upon academic request and with permission of the Taiwan National Health Insurance Administration.

\section{Ethics approval and consent to participate}

This study was approved by the Institutional Review Board of National YangMing University (YM107035E). In accordance with regulations of the National Health Research Institutes, patient identification information was anonymized; therefore, informed consent was waived.

\section{Consent for publication}

Not applicable.

\section{Competing interests}

The authors declare that they have no competing interests.

\section{Author details}

${ }^{1}$ Department of Neurology, Taipei City Hospital, Taipei, Taiwan. ${ }^{2}$ Institute of Health and Welfare Policy, School of Medicine, National Yang-Ming University, Taipei, Taiwan. ${ }^{3}$ Master Program in Trans-disciplinary Long-Term Care and Management, National Yang-Ming University, Taipei, Taiwan. ${ }^{4}$ Department of Health Care Management, National Taipei University of Nursing and Health, Taipei, Taiwan.

Received: 18 June 2020 Accepted: 8 December 2020

Published online: 06 January 2021

\section{References}

1. American Medical Association. Recommendations of the conference on the guidelines for the categorization of hospital emergency capabilities. Chicago: AMA; 1973.

2. Mehrotra A, et al. Important historical efforts at emergency department categorization in the United States and implications for regionalization. Acad Emerg Med. 2010;17(12):e154-60.

3. National Academy of Sciences (US) . National Research Council (US) Committee on Trauma National Research Council (US) Committee on Shock, Accidental Death and Disability: The Neglected Disease of Modern Society. Washington (DC): National Academies Press (US); 1966. doi: https:// 
doi.org/10.17226/9978. 1966: National Academies Available from: https:// www.ncbi.nlm.nih.gov/books/NBK222962/.

4. Kocher KE, et al. Categorization, designation, and regionalization of emergency care: definitions, a conceptual framework, and future challenges. Acad Emerg Med. 2010;17(12):1306-11.

5. Boyd DR, et al. Categorization of hospital emergency medical capabilities in Illinois: a statewide experience. IMJ III Med J. 1974;146(1):33-8.

6. Detmer $\mathrm{DE}$, et al. Regional categorization and quality of care in major trauma. J Trauma. 1977;17(8):592-9.

7. Gibson G. Categorization of hospital emergency capabilities: some empirical methods to evaluate appropriateness of emergency department utilization. J Trauma. 1978;18(2):94-102.

8. Grumbach K, et al. Regionalization of cardiac surgery in the United States and Canada: geographic access, choice, and outcomes. JAMA. 1995;274(16): 1282-8.

9. DuBose JJ, et al. Effect of trauma center designation on outcome in patients with severe traumatic brain injury. Arch Surg. 2008;143(12):1213-7 discussion 1217

10. Mechem CC, et al. Resuscitation center designation: recommendations for emergency medical services practices. Prehosp Emerg Care. 2010;14(1):51-61.

11. Nguyen $Y L$, Kahn JM, Angus DC. Reorganizing adult critical care delivery: the role of regionalization, telemedicine, and community outreach. Am J Respir Crit Care Med. 2010;181(11):1164-9.

12. Hunt MM, et al. The utility of a "trauma $1 \mathrm{OP}$ " activation at a level 1 pediatric trauma center. J Pediatr Surg. 2017;52(2):322-6.

13. Windorski J, Reyes J, Helmer SD, Ward JG, Haan JM. Differences in hospital outcomes following traumatic injury for patients experiencing immediate transfer to a level I trauma facility versus resuscitation at a critical access hospital (CAH). Am Journal Surg. 2019;217(4):643-7.

14. Lyle DM, et al. Regionalization of trauma services in western Sydney: predicted effect on ambulance and hospital utilization rates. Aust N Z J Surg. 1991;61 (8):589-96.

15. Sampalis JS, et al. Trauma care regionalization: a process-outcome evaluation. J Trauma. 1999;46(4):565-79 discussion 579-81.

16. Miyata $\mathrm{H}$, et al. Toward quality improvement of cardiovascular surgery in Japan: an estimation of regionalization effects from a nationwide survey. Health Policy. 2009;91(3):246-51.

17. Diaz JJ Jr, et al. Does regionalization of acute care surgery decrease mortality? J Trauma. 2011;71(2):442-6.

18. Glickman SW, et al. Assessment of temporal trends in mortality with implementation of a statewide ST-segment elevation myocardial infarction (STEMI) regionalization program. Ann Emerg Med. 2012;59(4):243-52 e1.

19. Spaite DW, et al. Statewide regionalization of postarrest care for out-ofhospital cardiac arrest: association with survival and neurologic outcome. Ann Emerg Med. 2014;64(5):496-506 e1.

20. Kelly ML, et al. Decreased mortality in traumatic brain injury following regionalization across hospital systems. J Trauma Acute Care Surg. 2015; 78(4):715-20.

21. Tung YC, Chang GM. The relationships among regionalization, processes, and outcomes for stroke Care: a Nationwide population-based study. Medicine (Baltimore). 2016;95(15):e3327.

22. Velt KB, et al. Emergency department overcrowding: a survey among European neurotrauma centres. Emerg Med J. 2018;35(7):447-8.

23. Boyle $\mathrm{A}$, et al. Comparison of the international crowding measure in emergency departments (ICMED) and the National Emergency Department Overcrowding Score (NEDOCS) to measure emergency department crowding: pilot study. Emerg Med J. 2016;33(5):307-12.

24. Wang $Z$, et al. Causes of emergency department overcrowding and blockage of access to critical Services in Beijing: a 2-year study. J Emerg Med. 2018;54(5):665-73.

25. Horwitz LI, Bradley EH. Percentage of US emergency department patients seen within the recommended triage time: 1997 to 2006. Arch Intern Med. 2009;169(20):1857-65.

26. Wallingford $\mathrm{G} J$ r, et al. Introduction of a horizontal and vertical Split flow model of emergency department patients as a response to overcrowding. J Emerg Nurs. 2018;44(4):345-52.

27. Trzeciak S, Rivers EP. Emergency department overcrowding in the United States: an emerging threat to patient safety and public health. Emerg Med J. 2003;20(5):402-5.

28. Pines JM, Hollander JE. Emergency department crowding is associated with poor care for patients with severe pain. Ann Emerg Med. 2008:51(1):1-5.
29. Cowan RM, Trzeciak S. Clinical review: emergency department overcrowding and the potential impact on the critically ill. Crit Care. 2004;9(3):291.

30. Schull MJ, et al. Emergency department crowding and thrombolysis delays in acute myocardial infarction. Ann Emerg Med. 2004;44(6):577-85.

31. Makary MA, Daniel M. Medical error-the third leading cause of death in the US. BMJ. 2016;353:i2139.

32. Momeni M, et al. Emergency overcrowding impact on the quality of Care of Patients Presenting with acute stroke. Adv J Emerg Med. 2018;2(1):e3.

33. Asplin, B.R., et al., A conceptual model of emergency department crowding. Ann Emerg Med, 2003a. 42(2): p. 173-180.

34. Aday LA, Andersen R. A framework for the study of access to medical care. Health Serv Res. 1974;9(3):208.

35. Payne SM. Identifying and managing inappropriate hospital utilization: a policy synthesis. Health Serv Res. 1987;22(5):709-69.

36. Ministry of Health and Welfare. The Statistics and Trends in Health and Welfare 2019: Ministry of Health and Welfare; 2020

37. Lin C-Y, Lee Y-C. Appropriateness of emergency care use: a retrospective observational study based on professional versus patients' perspectives in Taiwan. BMJ Open. 2020;10(5):e033833.

38. Billings J, Parikh N, Mijanovich T. Emergency department use: the New York story. New York: Commonwealth Fund; 2000.(Issue Brief No. 434). 2000 [cited 2017 April 15].

39. Ballard DW, et al. Validation of an algorithm for categorizing the severity of hospital emergency department visits. Med Care. 2010:48(1).

40. Gandhi SO, Sabik L. Emergency department visit classification using the NYU algorithm. Am J Manag Care. 2014;20(4):315-20.

41. Wharam JF, et al. Emergency department use and subsequent hospitalizations among members of a high-deductible health plan. JAMA. 2007;297(10):1093-102

42. Longitudinal Health Insurance Database 2005(LHID2005). Accessed August 20, 2018; Available from: https://nhird.nhri.org.tw/en/Data_Subsets.html.

43. National Health Research Institutes. National Health Insurance Research Database. [Accessed August 20, 2018.]; Available from: https://nhird.nhri.org. tw/en/.

44. Yang YT, et al. The relationship between accessibility of healthcare facilities and medical care utilization among the middle-aged and elderly population in Taiwan. Int J Qual Health Care. 2015;27(3):222-31.

45. Lam C, et al. Emergency department utilization can indicate early diagnosis of digestive tract cancers: a population-based study in Taiwan. Comput Methods Prog Biomed. 2014;115(3):103-9.

46. Hsieh C-Y, et al. Taiwan's National Health Insurance Research Database: past and future. Clin Epidemiol. 2019;11:349.

47. Cheng $\mathrm{CL}$, et al. Validation of the National Health Insurance Research Database with ischemic stroke cases in Taiwan. Pharmacoepidemiol Drug Saf. 2011;20(3):236-42.

48. Cheng $C-L$, et al. Validation of acute myocardial infarction cases in the national health insurance research database in Taiwan. J Epidemiol. 2014; 24(6):500-7.

49. Su VY-F, et al. Use of ICS/LABA combinations or LAMA is associated with a lower risk of acute exacerbation in patients with coexistent COPD and asthma. J Allergy Clin Immunol Pract. 2018:6(6):1927-35 e3.

50. Su VY-F, et al. Sleep apnea and risk of pneumonia: a nationwide populationbased study. Cmaj. 2014;186(6):415-21.

51. Aday LA, Andersen R, F.G., Health Care in the U.S. Equitable for Whom? Beverly Hills: Sage Publications; 1980. p. 1980.

52. Hoot NR, Aronsky D. Systematic review of emergency department crowding: causes, effects, and solutions. Ann Emerg Med. 2008;52(2):126-36 e1.

53. van Tiel $\mathrm{S}$, et al. Systematic review of frequent users of emergency departments in non-US hospitals: state of the art. Eur J Emerg Med. 2015; 22(5):306-15.

54. Feldman J. The NYU Classification System for ED Visits: WSHA Technical Concerns, vol. 14; 2010. p. 2010. Accessed on November, 2017.

55. Wolinsky FD, et al. Emergency department utilization patterns among older adults. J Gerontol Ser A Biol Med Sci. 2008;63(2):204-9.

56. Sempere-Selva T, et al. Inappropriate use of an accident and emergency department: magnitude, associated factors, and reasons —an approach with explicit criteria. Ann Emerg Med. 2001;37(6):568-79.

57. Tsai JC, Liang YW, Pearson WS. Utilization of emergency department in patients with non-urgent medical problems: patient preference and emergency department convenience. J Formos Med Assoc. 2010;109(7): $533-42$. 
58. Payne K, et al. An after hours gp clinic in regional Australia: appropriateness of presentations and impact on local emergency department presentations. BMC Fam Pract. 2017;18(1):86

59. Coster JE, et al. Why do people choose emergency and urgent Care services? A rapid review utilizing a systematic literature search and narrative synthesis. Acad Emerg Med. 2017;24(9):1137-49.

60. Afilalo J, et al. Nonurgent emergency department patient characteristics and barriers to primary care. Acad Emerg Med. 2004;11(12):1302-10.

61. Chan C-L, et al. The association between the availability of ambulatory care and non-emergency treatment in emergency medicine departments: a comprehensive and nationwide validation. Health Policy. 2013;110(2-3):271-9.

62. Gill JM, Riley AW. Nonurgent use of hospital emergency departments: urgency from the patient's perspective. J Fam Pract. 1996;42(5):491-7.

63. Chou S-C, et al. Analysis of a commercial insurance policy to deny coverage for emergency department visits with nonemergent diagnoses. JAMA Netw Open. 2018;1(6):e183731

64. Luque Ramos A, Hoffmann F, Spreckelsen O. Waiting times in primary care depending on insurance scheme in Germany. BMC Health Serv Res. 2018; 18(1):191.

65. Raven MC, et al. The effectiveness of emergency department visit reduction programs: a systematic review. Ann Emerg Med. 2016;68(4):467-83 e15.

66. Smulowitz PB, Friedman AB, Pines JM. Appropriations for "appropriate" visits: payment denials for emergency department care. Am J Emerg Med. 2018.

67. Dale J, et al. Safety of telephone consultation for "non-serious" emergency ambulance service patients. Qual Saf Health Care. 2004;13(5):363-73.

68. Todd TN. Using Data to Inform Appropriateness in Saskatchewan's Health Care System: A Snapshot of Low Acuity Emergency Department Use: Faculty of Graduate Studies and Research, University of Regina; 2017.

69. Hopkins A, Fitzpatrick R, Foster A. What do we mean by appropriate health care. Qual Health Care. 1993;2(1):17-1.

70. David M, et al. Emergency outpatient services in the city of Berlin: factors for appropriate use and predictors for hospital admission. Eur J Emerg Med. 2006;13(6):352-7.

71. Moss C, et al. Patient experience in the emergency department: inconsistencies in the ethic and duty of care. J Clin Nurs. 2015;24(1-2):275-88.

72. Jeffery MM, et al. Validation of an algorithm to determine the primary care treatability of emergency department visits. BMJ Open. 2016;6(8):e011739.

73. Liberati A, et al. A European project assessing the appropriateness of hospital utilization: background, objectives and preliminary results. Int J Qual Health Care. 1995;7(3):187-99.

74. Lowe RA, Abbuhl SB. Appropriate standards for "appropriateness" research. Ann Emerg Med. 2001;37(6):629-32

75. Tsai JC, Chen WY, Liang YW. Nonemergent emergency department visits under the National Health Insurance in Taiwan. Health Policy. 2011;100(2-3): 189-95

76. Combes J, Arespacochaga E. Appropriate use of medical resources. Chicago: American Hospital Association, Physician Leadership Forum; 2013.

77. Begley CE, Lairson D, Morgan RO, Rowan PJ, Balkrishnan R. Evaluating the Healthcare System: Effectiveness, Efficiency, and Equity. 4th ed. Chicago: Health administration, Press; 20

\section{Publisher's Note}

Springer Nature remains neutral with regard to jurisdictional claims in published maps and institutional affiliations.

\section{Ready to submit your research? Choose BMC and benefit from:}

- fast, convenient online submission

- thorough peer review by experienced researchers in your field

- rapid publication on acceptance

- support for research data, including large and complex data types

- gold Open Access which fosters wider collaboration and increased citations

- maximum visibility for your research: over $100 \mathrm{M}$ website views per year

At $\mathrm{BMC}$, research is always in progress.

Learn more biomedcentral.com/submissions 